\title{
小议 “犹豫”
}

于玲利

西南民族大学

DOI:10.32629/mef.v2i11.369

[摘 要] “犹豫” 一词, 是汉语中的常用词汇, 但许多人对其来源却不甚明了。清代以前, 学者们从词形的角度训释 “犹豫”一词,认为 “犹” 和 “豫”为两种动物。这种说法大约是清代之前被学者广泛接受的一种解释,但实为讹误, “犹豫” 为双声联绵词而非合成词。 [关键词] “犹豫”; 联绵词; 双音词

\section{On "Hesitation" \\ Yu Lingli}

\section{Southwest Minzu University}

[Abstract] The word "hesitation" is a common vocabulary in Chinese, but many people do not know its origin. Prior to the Qing Dynasty, scholars interpreted the word "hesitation" from the perspective of word form, thinking that "You" and "Yu" are two kinds of animals. This kind of statement was an explanation widely accepted by scholars before the Qing Dynasty, but it was a mistake, and "hesitation" was a disyllabic word rather than a compound word. [Keywords] "hesitation"; polysyllabic words; disyllabic words

\section{1 “犹豫” 为联绵词}

1. 1 旧说辨疑。早期辞书典籍如《说文》、《尔雅》、《颜氏 家训》等, 多从 “犹豫” 一词的书写符号入手, 穿丵附会, 认为 “犹” 和 “豫” 为二兽名。如: 《尔雅 - 释兽》: “犹如鹿, 善登木。”《说文》: “獾属。从犬酋声。一曰陇西谓犬子为犹。 以周切”。《颜氏家训・书证第十七》: “《离骚》曰: “心犹豫 而狐疑。” 先儒未有释者。案: 《户子》曰: “五尺犬为犹。《说 文》云: ‘陇西谓犬子为犹。” 吾以为人将犬行, 犬好豫在人前, 待人不得, 又来迎候, 如此往还, 至于终日, 斯乃豫之所以为未 定也, 故称犹豫。或以《尔雅》曰: “犹如鹿, 善登木。’ 犹, 兽 名也, 既闻人声, 乃豫缘木, 如此上下, 故称犹豫”。北魏郦道元 在《水经注 - 江水一》中道: “山多犹猢, 似猴而短足, 好游岩 树, 一腾百丈, 或三百丈, 顺往倒返, 乘空若飞。” “豫”, 据《说 文・象部》记载: “豫, 象之大者。”旧说 “豫” 这种象, 体型 庞大, 动作不灵巧, 且遇事迟疑, 左右摇摆不定。人们因这两种 动物有生性多疑的共同特征, 故经常用这两种动物的名称来 形容缺少主见, 遇事难以下决定的心态或行为。

古人的以上说法, 有两点不妥, 理由如下:

第一, 上述典籍中对于 “犹” 这种动物的形貌, 有三种不同 的说法, 且相互间几乎没有相同之处。《尔雅》中记载“犹如鹿”, 据李時珍《本草纲目》记载: “鹿居大山中, 似獐而小, 牡者有 短角, 黧色豹脚, 脚矮而力劲, 善跳越。其行草莽, 但循一径。皮 极细淢, 靴袜珍之。或云亦好食蛇。《汉语大词典》对 “鹿” 的释义是: “哺乳动物的一种。是小型的鹿, 雄的有长牙和短 角。腿细而有力, 善于跳跃, 皮很柔软, 可以制革。常见品种有 黄鹿、黑鹿、赤鹿等。”从以上典籍对 “犹” 这种动物体貌的 形容可知, “犹” 是一种似獐似鹿的兽。根据《说文》对 “犹”
的解释可知, “犹” 是幼小的犬; 而据《水经注》记载, “犹” 是一种 “似猴而短足” 的动物。综上, 暂且不论 “犹” 这种动 物在古时是否真实存在, 想必即便真的存在也少有人亲眼目睹, 否则典籍中对其形貌的叙述又怎会有如此大的差距。既然这种 动物如此少见, 那么我们不能不怀疑, 古人对其习性的描写可 能出于个别人的主观臆测。因此, 认为 “犹豫” 一词中的 “犹” “豫” 二字为兽名, 二者因语义相关构成合成词的说法, 稍显珲 强。第二, 上文提到, 古籍中对 “犹” 的记载相互矛盾, 实不可 信。此外, 文献古籍中对 “犹” 和 “豫” 这两种动物的记载也 甚少见。如今互联网的信息覆盖十分全面, 可当我们搜索 “犹” 和 “豫” 这两种动物时, 不仅形象无从查询, 文字记载的资料也 几乎没有。可见, 我们找不到实例来证明这两种动物真实存在。

王念孙在《经义述闻》中云: “夫双声之字, 不求诸声而 求诸字, 固宜其说之多業也。”很多古代学者, 都因不明联绵词 的这一特点, 误解 “犹豫”一词。除上述学者外, 朱喜、洪兴 祖、孔颖达、叶梦得等古代学者也对这个词作出误释。如: 叶梦得在《岩下放言》中云: “先事而戒谓之 ‘豫”, 后事而 戒谓之 “犹”。犹豫, 本二兽名。古语因物取义, 往往便以其物 名之。后世沿袭, 但知其义, 不知其物, 遂妄为穿丵, 未有不悮 者。”直至清代, 王念孙、段玉裁、黄生等学者才提出了新的 观点。如王念孙在 《读书杂志》中云: “犹豫双声字, 犹楚辞 之言夷犹耳, 非谓兽畏人而豫上树, 亦非谓犬子豫在人前。”

1.2 “犹豫 “一词具有联绵词的普遍特征。(1) 两字有双 声的语音联系。双音节联绵词上下字之间多有语音上的联系, “犹”、“豫”二字从古至今语音上都有相似之处。“犹”的上 古音为西母幽部, “豫” 的上古音为予母鱼部; 根据《广韵》 记载, “犹”的音韵地位为“流摄开口三等平声尤韵以母”; “豫” 
的音韵地位为 “遇摄开口三等去声鱼韵以母” , 二字不仅声母 相同, 且等和呼具有同一性。据《中原音韵》, “犹” 和 “豫” 均属影母字, 二字在语音上具有双声的关系。(2)书写形式不 定。联绵词具有义存乎声的特点, 因而书写形式多变, 一个联 绵词往往有诸多书写形式, 偶尔上下字可互换位置。“犹豫” 一词在古籍中有多种写法, 如 “犹与”:

酒也, 计念进之, 则杀主父, 不义; 言之, 又杀主母, 不忠。 犹与因阳僵覆酒。” (《列女传・周主忠妾》)

又作 “犹预”, 如: “必定犹预, 即是保也, 扶君顺师, 周 匝入道, 即是相也。” (《史论・太平经》)

又作 “犹疑”, 如: “幽求犹疑未敢前。” (《博异志 - 白 幽求》)

又作 “犹与” , 如: “秦惠王欲先伐韩, 恐蜀乱; 先伐蜀, 恐韩袭秦之弊, 犹与未决。”

\section{(《新序》)}

又作 “九豫”, 如: “器将王元说器, 多设疑故, 久它豫不 决。”(《后汉书・来歌传》)

又作 “容与”, 如: “忽吾行此流沙兮, 遵赤水而容与。” (《楚辞・离骚》)

又作 “犹夷”, 如: “国士如君无二, 当一诺怎得犹夷。” （《易水寒》第一折）

又作 “夷犹”, 如: “君不行兮夷犹, 塞谁留兮中洲。” 《楚 辞・九歌・云中君》)

此外, 还有 “犹移”、“由与”、“由豫”、“尤与”、“由夷”、 “遊豫” 等书写形式。从上述的例子当中可以看出, “犹豫” 一词的书写形式具有多样化的特点, 且这些书写形式之间无 本字借字之分, 也不存在假借现象。这是因为联绵词多记音 表义, 在语言发展过程中, 联绵词的语音会略有变化, 记录这 种语音的符号自然会有所不同, 加之方音等因素的影响, 使 得大部分联绵词有多种书写形式。

以上多种书写形式足以说明, “犹豫” 二字为一个语素, 不能分开解释, 否则我们将无从解释上述词语中的 “由”、 “容”、“与”、“夷” 等字的意义。(3) 上下字逐渐趋于同化。 上文提到, “犹豫” 二字在漫长的历时演变中, 有过多种书写 形式, 但其在现代汉语书面语中的书写形式已经基本固定为 “犹豫”二字, 这一特征同样符合双音节联绵词的普遍特点。

“义寄于声” 是联绵词的根本特点, 但汉字是表意体系 的文字, 由形辨义几乎已经成为使用汉字的全体社会成员约 定俗成的认字方式, 这种思维方式顽强地渗入到记录联绵词 符号中。例如 “狼狈”一词在古籍中有 “狼跋”、“刺八”、

“獵跋”、“狼贝”等多种书写形式, 这些书写形式在汉字使 用过程中被一一淘汰, 如今 “狼狈” 二字已成为记录这一词 义的固定书写形式。汉字的表意特征, 使得形义脱节的联绵 词逐渐被 “同化”, 在字形上逐渐被赋予标示义类的形符, 其表意功能也愈加明朗化。汉语中存在很多类似的词语, 如 “勿做——忽悠”、“丁宁——叮咛”、“荣原——蝶螈”、“朱
儒——侏儒”等。

长期以来, 古人对 “犹豫” 一词的语源都存有误解, 认为 这个词来源于两种动物的名词, 于是表示兽名的 “犹” “豫” 二字, 便自然而然地在上文中提到的多种书写形式的竞争中 “取得胜利”。

\section{2 “犹豫” 质疑}

“犹豫”一词是双声联绵词而非合成词的观点, 已得到学 者们广泛认可。但笔者在考释这一词语的过程中, 发现将 “犹 豫” 一词归为联绵词仍有些不妥之处。首先, 目前的学术著作, 对 “联绵词” 的定义皆包含以下两点要素: 一是, 两个音节连 缀成义, 无法单独成义; 二是, 只包含一个语素, 不可拆分。然 而, “犹” 和 “豫” 都可以单独使用, 表 “犹豫” 义。例如: “豫 兮, 若冬涉川; 犹兮, 若畏四邻” (《道德经》), “喜心而不豫 兮, 㒸不可保也。”(《楚辞・九章・惜诵》) 王逸注: “豫, 犹豫也。” “余将董道而不豫兮, 固将重昏而终身。” (《楚辞・九章・涉江》)

其次, 上文提到, 书写形式多样是联绵词的主要特征之 一。但事实上, 不仅联绵词具有书写形式多样的特征, 很多双 音节合成词也有很多异形。如明代方以智《通雅》考辨的謰 语近五百余条, 每条都有不同的书写形式, 但其中除联绵词 外还有合成词和词组。

\section{3 结语}

综上所述, 我们可以得出以下几点启示: 一、联绵词与双 音节合成词密切相关。“犹豫”一词在形成发展过程中, 曾有过 分用的情况, 这点与双音节合成词的发展轨迹相同。笔者认为, 现如今我们所判定的部分联绵词, 很有可能是由合成词发展而 来。例如 “犹豫” 一词, 在其还没有固定成形时, 不仅可以单用 而且上下字位置可以互换, 因此, 我们完全有理由相信, 在成词 之初, “犹” 和 “豫” 二字都具有实在意义。受汉语双音节化 的影响, 这两个词经常在一起使用, 加之两个词各自所表示的 语义使用频率极低, 久而久之, 二者本身的语义便模糊了, 只能 连缀成义。第二、判定一个词是否是联绵词, 应该从历时的角 度去考察。传统语文学著作中有 “连语”、“连字”、“謰语”、“连 绵字” 等术语名词, 这些名词与我们今天所说的 “联绵词” 并 不是等同的概念, 在考释某些词语时, 应注意到这一区别。

记录联绵词的符号只是单纯的记音, 没有表意功能, 而 不借助于现代科技, 声音是无法记录保存下来的, 这也是探 究联绵词的一大难点。总而言之, 联绵词的领域里还有很多 内容值得我们深入探究。

\section{[参考文献]}

[1]颜之推.颜氏家训[M].天津:天津古籍出版社,1995:167-168.

[2]王念孙.读书杂志[M].江苏:江苏古籍出版社,1985:219.

[3]郭在贻.训诂学[M].北京:中华书局,2005:95.

\section{作者简介：}

于玲利(1994--), 女,汉族,吉林公主岭市人,西南民族大 学文学与新闻传播学院2017级汉语言文字学专业在读研究 生,研究方向：文字学、汉语史。 